Int. J. Electrochem. Sci., 15 (2020) 9888 - 9901

International Journal of

ELECTROCHEMICAL

SCIENCE

$\underline{\text { www.electrochemsci.org }}$

\title{
A Simple Ultrasensitive Electrochemical Biosensor for Simultaneous Determination of Dopamine, Uric Acid and Ascorbic Acid Based on $\beta$-cyclodextrin/selenium Doped Carbon Quantum Dots Modified Glassy Carbon Electrode
}

\author{
Guojie Huang ${ }^{1}$, Xiaoling Yang ${ }^{1}$, Ruihui Huang, Zhihong Yan ${ }^{1, *}$, Fuqiang Sun ${ }^{1}$, Li Xu ${ }^{1}$, Yi Liu ${ }^{1,2, *}$ \\ ${ }^{1}$ College of Pharmacy, Guangdong Pharmaceutical University,Guangdong, China. \\ ${ }^{2}$ School of Chemistry and Chemical Engineering,Guangdong Pharmaceutical University, Guangdong, \\ China. \\ *E-mail: yzhxsp@aliyun.com, 1499088964@qq.com
}

doi: $10.20 .964 / 2020.10 .47$

Received: 10 May 2020 / Accepted: 17 July 2020 / Published: 31 August 2020

\begin{abstract}
In this work, a novel electrochemical sensor for the simultaneous determination of ascorbic acid (AA), dopamine (DA) and uric acid (UA) was successfully prepared by using $\beta$-cyclodextrin ( $\beta$-CD) / Se doped carbon quantum dots (Se-CQDs) modified glassy carbon electrode (GCE). The $\beta$-CD/Se-CQDs composite was characterized by the TEM and FTIR. The electrochemical behaviors of AA, DA and UA on the modified electrode were investigated by cyclic voltammetry, electrochemical impedance spectroscopy and differential pulse voltammetry. AA, DA, and UA can be separated well due to the synergistic effect of $\beta-\mathrm{CD}$ and Se-CQDs. The three oxidation peaks current were linearly with the concentration range of $10 \sim 1400 \mu \mathrm{M}, 60 \sim 1000 \mu \mathrm{M}$ and $10 \sim 1000 \mu \mathrm{M}$ for AA, DA, and UA, respectively, with the limits of detection of $0.06,0.02,0.03 \mu \mathrm{M}(\mathrm{S} / \mathrm{N}=3)$. Moreover, as-prepared biosensor exhibited prominent selectivity, stability and reproducibility and it was used for the simultaneous determination of AA, DA, and UA in in human serum and urine samples with satisfactory results.
\end{abstract}

Keywords: $\beta$-cyclodextrin, Carbon quantum dots, Ascorbic acid, Dopamine, Uric acid.

\section{$\underline{\text { FULL TEXT }}$}

(C) 2020 The Authors. Published by ESG (www.electrochemsci.org). This article is an open access article distributed under the terms and conditions of the Creative Commons Attribution license (http://creativecommons.org/licenses/by/4.0/). 